\title{
Betaine Lipids in Lower Plants. Biosynthesis of DGTS and DGTA in Ochromonas danica (Chrysophyceae) and the Possible Role of DGTS in Lipid Metabolism
}

\author{
Guido Vogel and Waldemar Eichenberger
}

Department of Biochemistry, University of Bern, Switzerland

\begin{abstract}
Membrane lipids and fatty acids of Ochromonas danica were analyzed. Of the two betaine lipids, the homoserine lipid DGTS mainly contains $14: 0$ and 18:2 fatty acids, while the alanine lipid DGTA is enriched in 18:0, 18:2 and 22:5 fatty acids. Of the polar moiety of DGTA, improved NMR data are presented. On incubation of cells with $\left[3,4-{ }^{14} \mathrm{C}\right]$ methionine, DGTS as well as DGTA were labelled. With $\left[1-{ }^{14} \mathrm{C}\right]$ methionine as a substrate, the label appeared in DGTS only. If double labelled $\left[{ }^{3} \mathrm{H}\right]$ (glycerol)/ $\left[{ }^{14} \mathrm{C}\right]$ (polar part)DGTS was used as a precursor, radioactivity was incorporated specifically into DGTA in which the isotope ratio was unchanged compared to the precursor. Thus, the glyceryltrimethylhomoserine part of DGTS acts as the precursor of the polar group of DGTA. Labelling of cells with $\left[1-{ }^{14} \mathrm{C}\right]$ oleate in a pulse-chase manner and subsequent analysis of the label in the fatty acids and molecular species of different lipids including DGTS and DGTA, suggested a clearly different role of the two betaine lipids: DGTS acts as a i) primary acceptor for exogenous $C_{18}$ monoene acid, ii) substrate for the desaturation of 18:1 to 18:2 acid, and iii) donor of mainly 18:2 fatty acid to be distributed among PE and other membrane lipids. Into DGTA, in contrast, fatty acids are introduced only after elongation and desaturation. As a result, the biosynthesis of DGTA from DGTS involves a decarboxylation and recarboxylation of the polar part and a simultaneous deacylation and reacylation of the glycerol moiety.
\end{abstract}

Key words: Betaine lipids - Biosynthesis - DGTA - DGTS - Fatty acids - Ochromonas.

The betaine lipids DGTS (=DGTH, diacylglyceryltrimethylhomoserine, homoserine lipid) and DGTA (diacylglycerylhydroxymethyltrimethyl- $\beta$-alanine, alanine lipid) are lipid components of a number of plants. The distribution of betaine lipids has been described by Sato and Furuya $(1984,1985)$, Eichenberger (1982) and Araki et al. (1991). In these plants all of which belong to the cryptogamic but not the flowering plants, betaine lipids represent a third group of membrane lipids beside the common

Abbreviations: BPG, bisphosphatidylglycerol; CSL, chlorosulfolipid; DAG, diacylglycerol; DGDG, digalactosyldiacylglycerol; DGTA, diacylglycerylhydroxymethyltrimethyl- $\beta$-alanine; DGTS, diacylglyceryltrimethylhomoserine; FFA, free fatty acids; FID, flame ionization detector; GLC, gas liquid chromatography; MGDG, monogalactosyldiacylglycerol; PC, phosphatidylcholine; PE, phosphatidylethanolamine; PG, phosphatidylglycerol; PI, phosphatidylinositol; SQDG, sulfoquinovosyldiacylglycerol; TAG, triacylglycerol; $a 18: 3,18: 3(9,12,15), a$-linolenic acid; $\gamma 18: 3,18: 3(6,9,12), \gamma$-linolenic acid; RP-HPLC, reversed-phase high performance liquid chromatography. phospholipids and glycolipids.

The biosynthesis of betaine lipids has not been elucidated in detail, although it was shown in Chlamydomonas reinhardtii (Sato 1988) and in Marchantia (Sato and Kato 1988) that methionine was a potent precursor of both the carbon backbone and the $N$-methyl groups of the polar head group of DGTS. The close structural relationship between the polar groups of DGTS and DGTA in which the carboxyl group has formally been shifted from one carbon atom to the next one, also suggested a close relationship between the biosynthetic pathways of these compounds. Since at the beginning of our work, Ochromonas was the only organism known to produce both DGTS and DGTA, this alga was chosen for biosynthetic studies. In a preliminary article, evidence was provided that DGTS has a precursor function in the biosynthesis of DGTA in Ochromonas (Vogel and Eichenberger 1990). In order to provide evidence for the incorporation of radiolabelled methionine specifically into the betaine lipids and for the definite intramolecular localization of the label, additional experiments were carried out. Also, labelling of cells with 
oleic acid had to be done, in order to trace the path of fatty acids linked to the betaine lipids and other glycerolipids of Ochromonas. Very recently, labelling experiments with Cryptomonas CR-1 also strongly suggested a transformation of DGTS to DGTA by this unicellular cryptophyte (Sato 1991b).

\section{Materials and Methods}

Plant material-Cells of Ochromonas danica were grown in Erlenmeyer flasks $(150 \mathrm{ml})$ containing $35 \mathrm{ml}$ of medium according to either Pringsheim (1955) or Aaronson and Baker (1959), at $26^{\circ} \mathrm{C}$ under continuous fluorescent light (Vogel et al. 1990).

Lipid isolation and determination-Lipids were extracted with methanol containing $0.05 \%$ butyl hydroxytoluene as an antioxidant. They were separated on precoated silica gel plates (Merck 5715) with chloroform/ methanol/water $(65: 25: 4$, by vol.) in the 1st dimension and with chloroform/methanol/isopropylamine/conc. ammonia $(65: 35: 0.5: 5$, by vol.) in the 2 nd dimension. Spots were detected under UV (366 nm) after spraying with $2^{\prime}, 7^{\prime}$-dichlorofluoresceine. Quantitatve determination of lipids was obtained by quantitative determination of their constituent fatty acids by GLC using behenic (22:0) acid methyl ester as an internal standard.

Fatty acid analysis-Fatty acid methyl esters were obtained either from total lipids by alkaline hydrolysis with methanolic $\mathrm{KOH}$ and methylation of the free fatty acids with diazomethane (Eichenberger 1976) or from pure lipids by transesterification with sodium methoxide (Thies 1971). For GLC separation, a Shimadzu GC-8A or GC-14A equipped with FID was used. The column was a fused silica capillary column, $25 \mathrm{~m}$ long, $0.25 \mathrm{~mm}$ I.D., coated either with Carbowax $20 \mathrm{M}$ (chemically bound) operated at $175-220^{\circ} \mathrm{C}\left(1^{\circ} \mathrm{C} \mathrm{min}{ }^{-1}\right)$ or Restek RTX-2330 (chemically bound), operated at $170-210^{\circ} \mathrm{C}\left(2^{\circ} \mathrm{C} \mathrm{min}-1\right) . \mathrm{H}_{2}$ was used as carrier gas and for integration of peaks, either a Shimadzu C-R3A or C-R4A integrator was used.

Phenacylesters of fatty acids were prepared from free fatty acids according to Borch (1975) in a microvial which had been treated with dichlorosilane before. Phenacylesters were separated by reversed-phase HPLC by loading 20 $\mu l$ of a solution in acetonitril on a column $(250 \times 4 \mathrm{~mm})$ containing Nucleosil $1005 \mathrm{C} 18$ (Macherey-Nagel, Düren, F.R.G.). Acetonitril (A) and acetonitril/water $(6: 4, v / v)$ (B) were used as solvents. The flow rate was $1.5 \mathrm{ml} \mathrm{min}-1$ and the linear gradient from $80 \%$ B to $20 \%$ B in $80 \mathrm{~min}$. The phenacylesters were detected at $242 \mathrm{~nm}$.

Separation of lipid molecular species-DGTS, DGTA and PE were eluted from TLC plates and then purified by HPLC. For DGTS, a column $(250 \times 4 \mathrm{~mm})$ of Spherisorb $S$ $3 \mathrm{NH}_{2} 3 \mu \mathrm{m}$ (Knauer) was used with acetonitril and water as solvents. The gradient was from $100 \%$ acetonitril to
$68 \%$ acetonitril in $40 \mathrm{~min}$ with a flow of $1.5 \mathrm{ml} \mathrm{min}^{-1}$. For DGTA and PE, Nucleosil $10010 \mu \mathrm{m}$ (Knauer) was used with acetonitril (A) and acetonitril/water $(8: 2, v / v)(B)$. The gradient was from $12.5 \%$ to $75 \% \mathrm{~B}$ in $5 \mathrm{~min}$ and then $75 \% \mathrm{~B}$ for $15 \mathrm{~min}$ at a flow of $1.5 \mathrm{ml} \mathrm{min} \mathrm{m}^{-1}$. Detection was at $210 \mathrm{~nm}$. For the separation of molecular species, a column $(250 \times 4 \mathrm{~mm})$ Nucleosil $1005 \mathrm{C} 185 \mu \mathrm{m}$ (Knauer) and methanol/water/acetonitril ( $80: 12: 8$, by vol.) (A) and methanol/water/acetonitril ( $94: 3.5: 2.5$, by vol.) with 20 $\mathrm{mM}$ choline chloride (B) were used as solvents. For DGTS and DGTA, the gradient was from $70 \%$ to $100 \% \mathrm{~B}$ in 40 $\mathrm{min}$, and for PE from $20 \%$ to $80 \% \mathrm{~B}$ in $40 \mathrm{~min}$. The flow was $1.5 \mathrm{ml} \mathrm{min}^{-1}$ and the detection at $202 \mathrm{~nm}$.

Incubation conditions-In a standard assay, 2-4.109 cells of the middle or late logarithmic phase $\left(3-5 \cdot 10^{7}\right.$ cells per $\mathrm{ml}$ ) were supended in $10 \mathrm{ml}$ of nutrient (Aaronson and Baker 1959). The suspension was incubated with $185 \mathrm{kBq}$ $\mathrm{L}-\left[3,4{ }^{14} \mathrm{C}\right]$ methionine $\left(2.18 \mathrm{GBq} \mathrm{mmol}{ }^{-1}\right)$ or $\left[1-{ }^{14} \mathrm{C}\right]$ methionine $\left(2.06 \mathrm{GBq} \mathrm{mmol}^{-1}\right)$.

For the incubation with labelled oleate, $2 \cdot 10^{9}$ cells were suspended in $6 \mathrm{ml}$ of nutrient medium and incubated for 1 hour with $2 \mu$ moles glycerol-3-phosphate and $370 \mathrm{kBq}$ ammonium- $\left[1-{ }^{14} \mathrm{C}\right]$ oleate obtained by neutralization of [1${ }^{14} \mathrm{C}$ loleic acid with an equimolar amount of ammonia. Cells containing $40 \%$ of the substrate supplied, were distributed among 5 Erlenmeyer flasks containing $40 \mathrm{ml}$ of nutrient each. Aliquots were taken after different times up to 24 hours of chase.

Preparation of double labelled DGTS-1.5 $10^{9}$ cells were suspended in $4 \mathrm{ml}$ nutrient and incubated for 8 hours with $2.66 \mathrm{MBq}\left[2-{ }^{3} \mathrm{H}\right]$ glycerol and $140 \mathrm{KBq}\left[3,4-{ }^{14} \mathrm{C}\right]$ methionine. Lipids were extracted and separated by 2-dim. TLC. The product contained $14 \mathrm{kBq}{ }^{3} \mathrm{H}$ in the glycerol part and $20.3 \mathrm{kBq}{ }^{14} \mathrm{C}$ in the polar part. For incubation, the substrate was solubilized in nutrient medium by sonication.

Radioactive measurements-The radioactive spots were localized on TLC plates by scanning the plate with a Bioscan System 200 Imaging Scanner (Bioscan, Washington, D.C.) linked to an IBM XT computer. Single spots and HPLC fractions were measured on a MR-300 Liquid Scintillation Counter (Kontron, Switzerland) after addition of $2 \mathrm{ml}$ methanol and $5 \mathrm{ml} \mathrm{0.7 \%} \mathrm{(w/v)} \mathrm{butyl-PBD} \mathrm{(Ciba-}$ Geigy, Basel, Switzerland).

Radioactive compounds $-\mathrm{L}-\left[1-{ }^{14} \mathrm{C}\right]$ methionine $(2.06$ $\left.\mathrm{GBq} \mathrm{mmol}{ }^{-1}\right)$ and $\left[1-{ }^{14} \mathrm{C}\right]$ oleate $\left(1.93 \mathrm{GBq} \mathrm{mmol}^{-1}\right)$ were purchased from Amersham International, $\mathrm{L}-\left[3,4-{ }^{14} \mathrm{C}\right] \mathrm{me}-$ thionine (2.18 GBq mmol $\left.{ }^{-1}\right)$ from Commissariat d'Energie Atomique, Gif-sur-Yvette, France, and $\left[2-{ }^{3} \mathrm{H}\right]$ glycerol $\left(370 \mathrm{GBq} \mathrm{mmol}{ }^{-1}\right.$ ) from New England Nuclear.

Nuclear magnetic resonance (NMR) and mass spectrometry (MS)-NMR spectra were measured in a methanol solution with a Bruker AM-400 spectrometer operating at $400.134 \mathrm{MHz}$ and $100.614 \mathrm{MHz}$ for ${ }^{1} \mathrm{H}$ - and ${ }^{13} \mathrm{C}-\mathrm{NMR}$, respectively. For FAB-MS, a VG ZAB 2 F instrument with 
a modified ion source and a self-constructed saddle-field atom gun $(5 \mathrm{kV}, 1 \mathrm{~mA}, \mathrm{Xe})$ was used. The sample was applied as a glycerol solution at an acceleration voltage of 8 $\mathrm{kV}$.

\section{Results}

Lipid composition of Ochromonas danica-A typical TLC separation of lipids is shown in Fig. 1 and the quantitative composition is given in Table 1.

Among glycerolipids which account for $41 \%$ of total lipids, DGTS is the most abundant component, followed by PE, DGDG, DGTA, PI, SQDG, PG, PC and BPG. Betaine lipids account for about $50 \%$ of the glycerolipids. It is to mention that within chloroplast lipids, the amount of DGDG exceeds MGDG by a factor of 1.5. For the sake of completeness, the amounts of TAG and of chlorosulfolipid as measured by other authors have also been added. Lipid $C$ is an as yet unidentified component which in most cases was not completely separated from SQDG and which does not react neither with molybdene blue nor Dragendorff reagent.

Fatty acid composition of O.danica-The fatty acid composition of total lipid and of single components is given in Table 2.

Major components are 18:2, 14:0 and a18:3 acids which account for $50 \%$ of total fatty acids. 18:1, $\gamma 18: 3$, 18:4, 20:4, 16:0 and 22:5 account for another $37 \%$, while of 18:0,20:2, 20:3 and 22:4 only minor amounts are present. The total fatty acid composition is similar to the one found by Nichols and Appleby (1969). Quantitative differences may be explained by the different culture conditions.

Among particular lipids, DGTS is enriched in 14:0 and 18:2, while in DGTA, 18:0, 18:2 and 22:5 acids predominate. Phospholipids generally are rich in 18:2, a18:3, 18:4 and 20:4 acids. Arachidonic and $\gamma 18: 3$ acids are concentrated in PE and BPG. MGDG and DGDG predominantly contain 18:2, a18:3 and 18:4 acids which account for more than $80 \%$ of the fatty acids in these lipids. This also indicates the predominance of "eukaryotic" molecular species occupied by $\mathrm{C}_{18}$ fatty acids in both positions of the glycerol part. SQDG as usual contains considerable amounts of saturated acids but also $18: 2$ and $a 18: 3$ acids.

Molecular species of DGTS and DGTA-In DGTS, 14:0/18:2 and 14:0/18:1 combinations are the predominant molecular species of DGTS, as obtained by reversed-phase HPLC and as demonstrated in Table 3.

In DGTA, the fatty acid pattern of which is completely different, 18:2/22:5, 18:1/22:5 and 18:0/22:5 combinations are the main molecular species as confirmed also by RP-HPLC (Table 3).

The pattern of molecular species of both DGTS and DGTA is in accordance with the fatty acid composition of

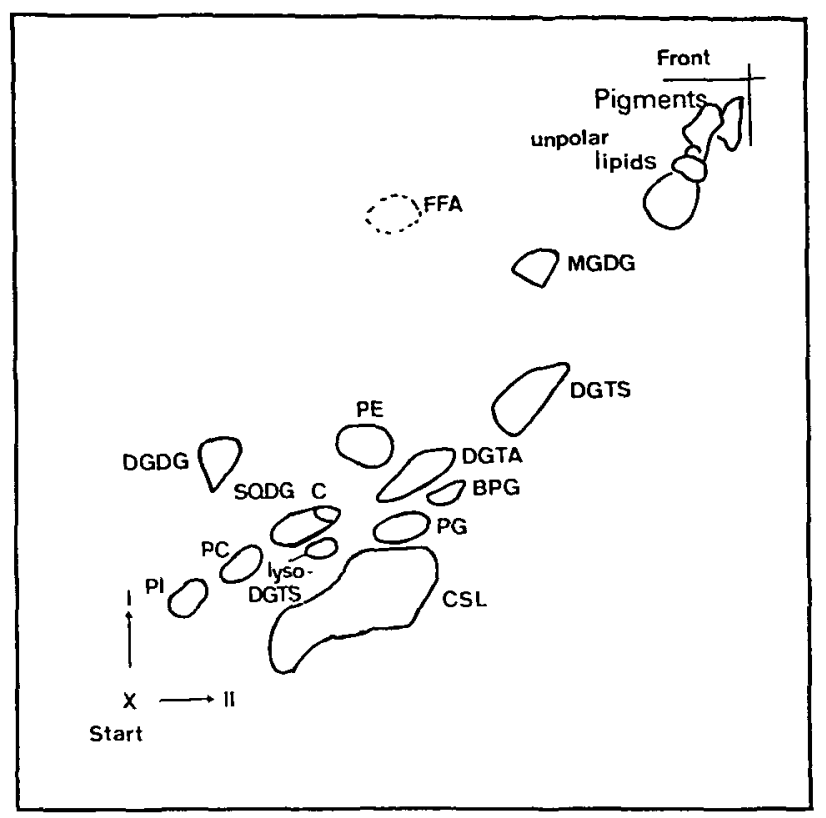

Fig. 1 2-dim. TLC of lipids from Ochromonas danica. Conditions see Materials and Methods.

these lipids (Table 2) and with the results obtained by FABMS (not shown here). With DGTS, prominent signals attributed to $(M+1)^{+}$ions could be observed at $m / e ~ 708$ and 710. With DGTA, the main signals were observed at $\mathrm{m} / \mathrm{e}$

Table 1 Lipid composition in cells of $O$. danica

\begin{tabular}{lcc}
\hline & $\begin{array}{c}\mu \text { g per mg } \\
\text { total lipid }\end{array}$ & $\begin{array}{c}\text { \% polar } \\
\text { lipid }\end{array}$ \\
\hline DGTS & 134 & 32.4 \\
DGTA & 50 & 12.1 \\
PE & 60 & 14.5 \\
PC & 10 & 2.4 \\
PI & 26 & 6.3 \\
BPG & 7 & 1.7 \\
PG & 14 & 3.4 \\
MGDG & 36 & 8.7 \\
DGDG & 54 & 13.0 \\
SQDG & $23^{c}$ & 5.5 \\
DAG & $\mathrm{tr}$ & \\
TAG & $250^{a}$ & \\
FFA & $20^{a}$ & \\
Pigments & $60^{a}$ & \\
Chlorosulpholipids & $253^{b}$ & \\
\hline
\end{tabular}

\footnotetext{
a Mazotti 1990.

${ }^{b}$ Brown und Elovson 1974.

c including small amounts of lipid C and lyso-DGTS.
} 
Table 2 Fatty acid composition in lipids of $O$. danica

\begin{tabular}{|c|c|c|c|c|c|c|c|c|c|c|c|}
\hline \multirow[b]{2}{*}{ Fatty acid } & \multicolumn{11}{|c|}{ mol $\%$ fatty acids } \\
\hline & $\begin{array}{l}\text { Total } \\
\text { lipid }\end{array}$ & DGTS & DGTA & PE & PC & PI & BPG & PG & MGDG & DGDG & ${ }^{a} \mathrm{SQDG}$ \\
\hline $14: 0$ & 13.1 & 36.0 & 3.1 & - & 1.4 & - & - & - & 0.6 & 8.0 & 7.0 \\
\hline $16: 0$ & 4.4 & 4.9 & 2.2 & 0.6 & 6.7 & 3.4 & $\operatorname{tr}$ & 5.7 & 0.5 & 1.3 & 7.9 \\
\hline $16: 1$ & $\operatorname{tr}$ & $\mathrm{tr}$ & - & - & - & tr & $\operatorname{tr}$ & - & $\operatorname{tr}$ & 0.7 & - \\
\hline 18:0 & 2.9 & 2.0 & 16.2 & - & 1.2 & tr & $\operatorname{tr}$ & $\operatorname{tr}$ & $\operatorname{tr}$ & 0.5 & 3.7 \\
\hline $18: 1$ & 6.8 & 7.5 & 6.7 & 2.4 & 6.2 & 11.4 & 2.4 & $\mathbf{t r}$ & 2.3 & 2.5 & 9.6 \\
\hline $18: 2$ & 26.0 & 30.7 & 17.6 & 26.7 & 35.7 & 33.1 & 18.6 & 43.7 & 30.0 & 24.7 & 33.1 \\
\hline$\gamma 18: 3$ & 6.9 & 6.7 & 3.1 & 10.1 & 6.1 & 3.4 & 9.1 & $\operatorname{tr}$ & 7.0 & 1.4 & 1.1 \\
\hline$a 18: 3$ & 12.3 & 3.0 & 1.5 & 15.7 & 20.9 & 11.1 & 14.9 & 24.7 & 34.3 & 41.1 & 21.6 \\
\hline $18: 4$ & 6.5 & 1.5 & 0.6 & 14.8 & 10.8 & 5.1 & 16.3 & 6.4 & 22.5 & 15.4 & 2.7 \\
\hline $20: 2$ & 2.4 & 1.7 & 1.5 & - & $\operatorname{tr}$ & 3.8 & - & $\operatorname{tr}$ & 0.6 & 0.9 & 0.5 \\
\hline $20: 3$ & 2.6 & 1.8 & 8.4 & - & 0.9 & 2.8 & $\mathrm{tr}$ & $\operatorname{tr}$ & 0.7 & 0.6 & 1.7 \\
\hline $20: 4(5,8,11,14)$ & 7.9 & 0.8 & 4.1 & 28.4 & 7.0 & 6.1 & 35.8 & 7.5 & 0.9 & 0.6 & 2.1 \\
\hline $22: 4$ & 1.2 & $\operatorname{tr}$ & 6.7 & - & - & 2.9 & $\operatorname{tr}$ & 一 & - & - & - \\
\hline $22: 5$ & 4.3 & 0.7 & 24.2 & - & - & 2.1 & $\operatorname{tr}$ & 一 & - & - & 1.8 \\
\hline
\end{tabular}

${ }^{a}$ including traces of lipid C. $\operatorname{tr}=$ trace.

814,812 and 810 (Vogel et al. 1990).

Improved NMR data of DGTA-For the first NMR analysis, chloroform was used as a solvent leading to spontaneous deamination during running the spectra (Vogel et al. 1990). Thus, because of the presence of decomposition products, certain signals of the polar group of the native lipid could not properly be assigned. Much better results were obtained when methanol was used as a solvent in which no degradation occurred.

The results shown in Table 4 fully confirm the struc-

Table 3 Molecular species of DGTS and DGTA of O. danica as obtained by RP-HPLC (major species are underlined)

\begin{tabular}{ccccc}
\hline \multicolumn{2}{c}{ DGTS } & & \multicolumn{2}{c}{ DGTA } \\
\cline { 1 - 2 } \cline { 5 - 5 } $\begin{array}{c}\text { Acyl } \\
\text { combination }\end{array}$ & mol. wt & & $\begin{array}{c}\text { Acyl } \\
\text { combination }\end{array}$ & mol. wt \\
\hline $14: 0 / 18: 4$ & 703 & & $18: 1 / 18: 1$ & 763 \\
$14: 0 / 18: 3$ & 705 & & $18: 1 / 20: 3$ & 787 \\
$14: 0 / 18: 2$ & 707 & & $18: 3 / 22: 5$ & 807 \\
$14: 0 / 18: 1$ & 709 & & $18: 2 / 22: 5$ & 809 \\
$15: 0 / 18: 2$ & 721 & & $\underline{18: 1 / 22: 5}$ & 811 \\
$15: 0 / 18: 1$ & 723 & & $18: 0 / 22: 5$ & 813 \\
$14: 0 / 20: 4$ & 731 & & $20: 4 / 22: 5$ & 833 \\
$14: 0 / 20: 3$ & 733 & & $20: 3 / 22: 5$ & 835 \\
$16: 0 / 18: 2$ & 735 & $22: 4 / 22: 5$ & 861 \\
$16: 0 / 18: 1$ & 737 & & \\
$18: 0 / 18: 2$ & 763 & & \\
\hline
\end{tabular}

ture of the polar group of DGTA, although three signals had to be re-attributed compared to our earlier interpretation (Vogel et al. 1990). For the methylene carbon adjacent to the ether bridge, a shift of $71.9 \mathrm{ppm}$ instead of $63.0 \mathrm{ppm}$ was observed in the ${ }^{13} \mathrm{C}-\mathrm{NMR}$. For the methene carbon, a signal at $45.7 \mathrm{ppm}$ (instead of 69.9) and for the methylene carbon adjacent to the ammonium group, a signal at 67.8 ppm (instead of 26.8) was measured.

Table $4{ }^{1} \mathrm{H}$ - and ${ }^{13} \mathrm{C}$-NMR signals of the polar group of DGTA

\begin{tabular}{ccc}
\hline Group & $\begin{array}{c}{ }^{\delta} \mathrm{H} \\
(\mathrm{ppm})\end{array}$ & $\begin{array}{c}{ }^{\delta} \mathrm{C} \\
(\mathrm{ppm})\end{array}$ \\
\hline A & $4.13 \mathrm{dxd}$ & 63.3 \\
& $4.30 \mathrm{dxd}$ & \\
B & $5.17 \mathrm{~m}$ & 71.2 \\
C & $3.52 \mathrm{dxd}$ & 69.8 \\
& $3.58 \mathrm{dxd}$ & \\
D & $3.42 \mathrm{dxd}$ & 71.9 \\
& $3.69 \mathrm{dxd}$ & \\
E & $2.8 \mathrm{~m}$ & 45.7 \\
F & $3.37 \mathrm{dxd}$ & 67.8 \\
& $3.84 \mathrm{dxd}$ & \\
G & $3.07 \mathrm{~s}$ & 53.5 \\
H & - & 173.5
\end{tabular}

Alphabetics refer to Figure 2. 


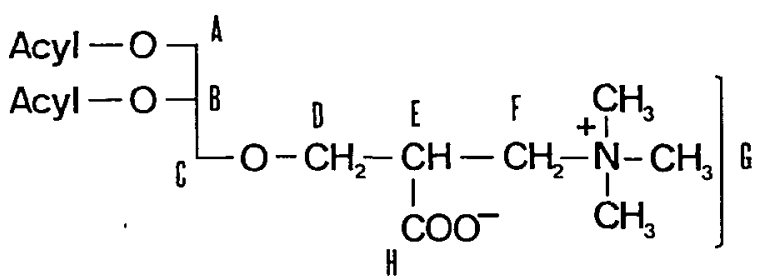

Fig. 2 Structure of DGTA. Alphabetics refer to groups in Table 4.

Biosynthesis of DGTS and DGTA-About $3 \cdot 10^{9}$ cells of $O$. danica were incubated with $185 \mathrm{kBq}\left[1-{ }^{14} \mathrm{C}\right]$ methionine or $\left[3,4-{ }^{14} \mathrm{C}\right]$ methionine in a 2.5 -hour pulse. After washing the cells free from labelled substrate, they were equally distributed among 8 Erlenmeyer flasks each containing $40 \mathrm{ml}$ of fresh nutrient. During the chase phase, aliquots were extracted after different times. The lipids were separated by 2-dimensional TLC and the radioactivity monitored in the particular lipid spots.

At the end of the pulse, about $25 \%$ of the substrate had been absorbed by the cells. Approximately one third of the radioactivity was found in the total lipid. During the chase of the growing culture, the radioactivity was measured in the lipids, in the protein fraction (TCA precipitation) and in the surrounding medium, as shown in Fig. 3.

At the end of the pulse, with both types of substrate, about $9 \%$ of the label of the substrate appeared in the lipid fraction where the maximum level was reached immediately after the 2-hour pulse. The label, however, rapidly decreased if $\left[1-{ }^{14} \mathrm{C}\right]$ methionine was used as a substrate, while it remained almost unchanged for the rest of the experiment, when $\left[3,4{ }^{14} \mathrm{C}\right]$ methionine was used. This result suggests that different pathways exist for the different labelled carbon atoms of the substrate. The label was partly incorporated also into the protein fraction reaching its maximum shortly after the end of the pulse and then weakly declining during the chase. It is to mention that in both cases the radioactivity continuously increased in the medium, possibly indicating a release of different labelled products.

In order to measure the labelling of particular lipids, the lipid extract from the incubation with $\left[3,4-{ }^{14} \mathrm{C}\right]$ methionine was separated by TLC and the single spots monitored. Of the total lipid label, even after 8-hour incubation, more than $95 \%$ were localized in betaine lipids, predominantly in DGTS, and only minor amounts also appeared in MGDG and in PC, as shown in Fig. 4.

After trans-esterification and measuring the radioactivity in both the organic phase (fatty acid methyl esters) and in the aqueous phase (polar group), in the betaine lipids the label was found almost exclusively in the polar part, as demonstrated in the inset of Fig. 4. In MGDG and PC, instead, an elevated labelling of acyl parts indicates that

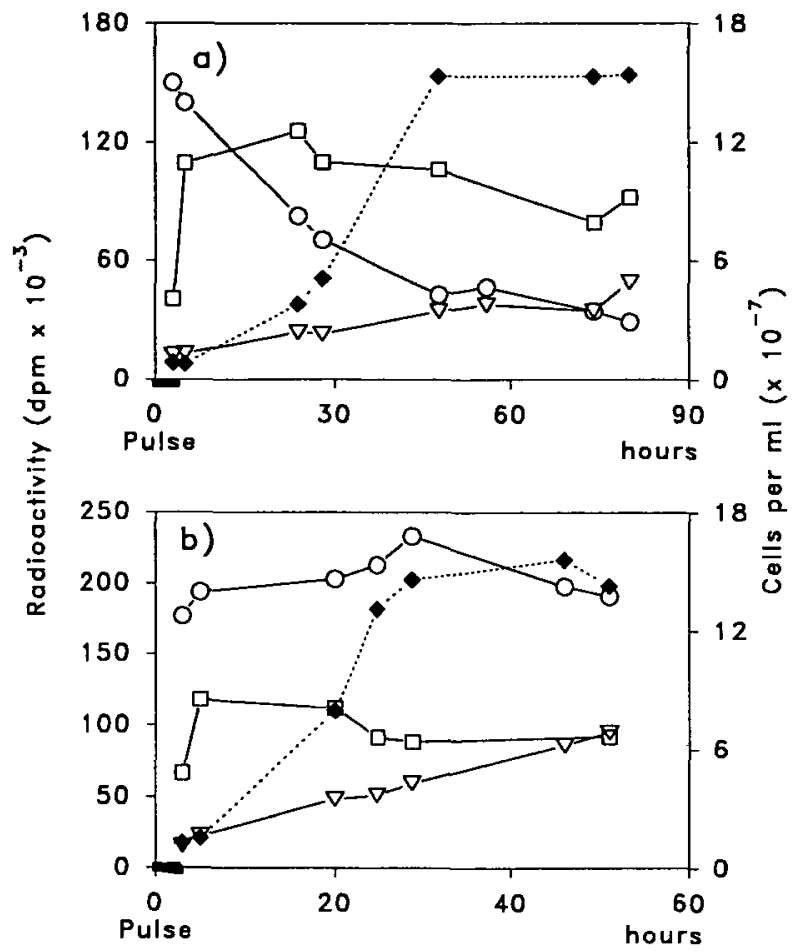

Fig. 3 Incubation of cells of $O$. danica with $\left[1-{ }^{14} \mathrm{C}\right]$ methionine (a) and $\left[3,4-{ }^{14} \mathrm{C}\right]$ methionine (b). Cell concentration $(\bullet)$, radioactivity in lipids $(O)$, protein fraction $(\square)$ and medium $(\nabla)$ during the chase phase.

small amounts of methionine are metabolized and the products used for fatty acid synthesis.

In order to measure the labelling in DGTS and DGTA

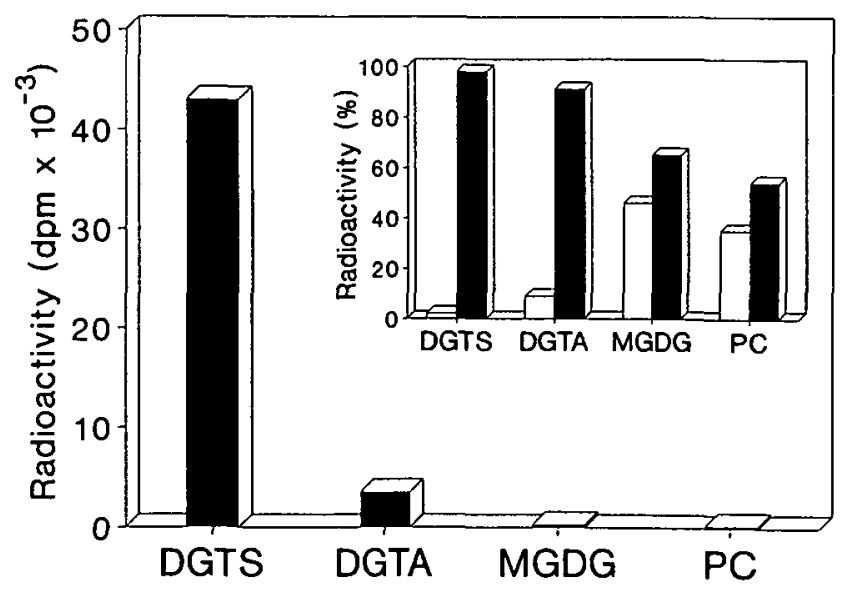

Fig. 4 Labelling of particular lipids on incubation of cells of O.danica for 8 hours with $\left[3,4^{14} \mathrm{C}\right]$ methionine. Inset: Distribution of label among fatty acyl (blank) and polar group (hatched). 
at different times of the chase phase, lipid samples were separated by unidimensional TLC and the traces monitored for radioactivity in a TLC scanner.

The results demonstrated in Figure 5 clearly indicate that, at the end of the pulse, the label exclusively appears in DGTS and continuously decreases within 66 hours of chase. In DGTA, in contrast, the label simultaneously increases. Since the total radioactivity (DGTS+DGTA) remains unchanged throughout the experiment, these findings suggest a metabolic conversion of the polar group of DGTS to DGTA. In order to properly confirm this process, cells were incubated with double labelled DGTS containing $0.38 \mu \mathrm{Ci}^{3} \mathrm{H}$ in the glycerol part and $20.3 \mathrm{kBq}{ }^{14} \mathrm{C}$ in the polar group. After incubation for 2 hours (pulse), $65 \%$ of the radioactivity was absorbed by or bound to cells. During the chase ( 48 hours), the lipids from aliquots were separated and the radioactivity measured in DGTS annd DGTA, as well as in the other glycerolipids. During the whole experiment, the label was limited to the betaine lipids (not shown). The labelling of DGTS rapidly decreases and corre-

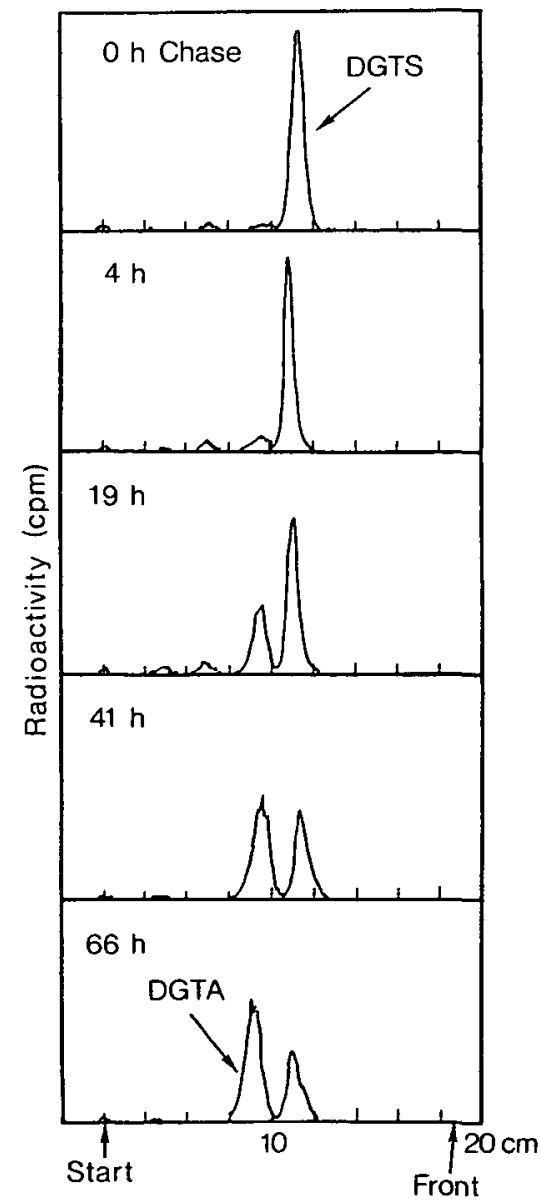

Fig. 5 Labelling of DGTS and DGTA after incubation of O. danica with $\left[3,4-{ }^{14} \mathrm{C}\right]$ methionine. spondingly increases in DGTA, as shown in Fig. 6a.

It is to mention that the tritium label (glycerol) clearly parallels the ${ }^{14} \mathrm{C}$ label (polar group) in DGTS as well as in DGTA. Small amounts of lyso compounds which arose during incubation are also included. The isotope ratio ${ }^{3} \mathrm{H} /{ }^{14} \mathrm{C}$ was found to be exactly the same for both DGTS and DGTA, as shown in Fig. 6b. Moreover, this ratio remains unchanged during the experiment. From these findings we conclude that the polar part including glycerol and $\mathrm{N}$-containing side chain of DGTS is transformed to give the polar group of DGTA. In addition, there is evidence that glycerol and $\mathrm{N}$-containing side chain are converted as antity, i.e. with the ether bond being conserved during the process.

These results clearly demonstrate that the biosynthesis of DGTA from DGTS involves a transformation of glycerol-bound $N, N, N$-trimethylhomoserine into hydroxymethyl- $N, N, N$-trimethyl- $\beta$-alanine. Since the two compounds are structural isomers differing by the position of the carboxyl group only, the process may include either a simple transfer of the carboxyl group from one carbon to the next or a decarboxylation/recarboxylation sequence in which the carboxyl group of DGTS is lost and replaced by a new one. In order to differentiate between the two possibilities, the lipids of cells which had been incubated in a pulse-chase manner with either $\left[1-{ }^{14} \mathrm{C}\right]$ - or $\left[3,4-{ }^{14} \mathrm{C}\right]-$ methionine were separated and the distribution of label

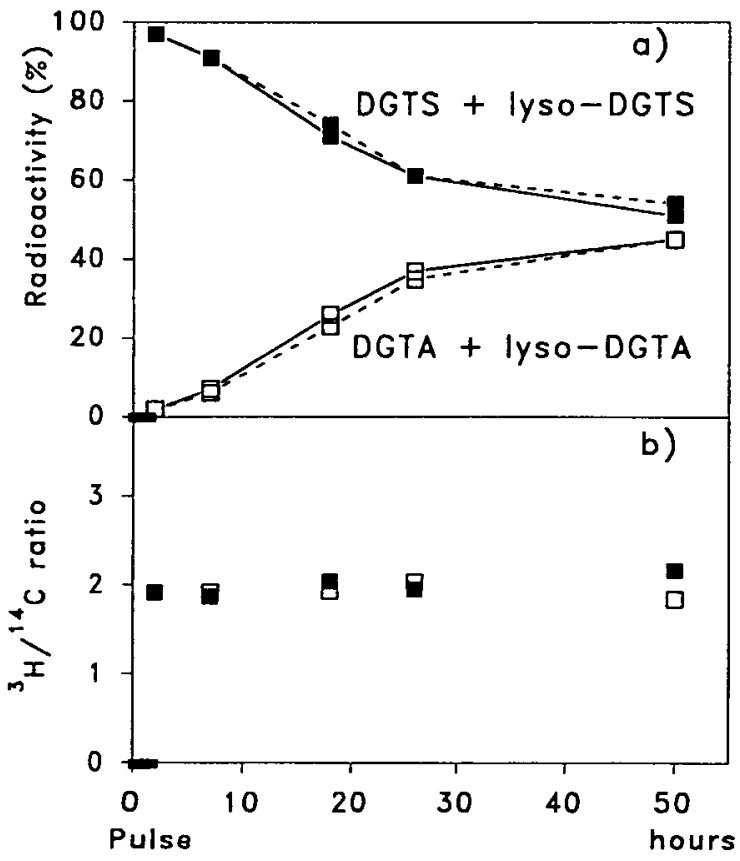

Fig. 6 Labelling of DGTS and DGTA after incubation of O. danica with double labelled DGTS. a) ${ }^{3} \mathrm{H}$ (glycerol, ----) and ${ }^{14} \mathrm{C}$ (polar part, $\rightarrow$ label and b) ${ }^{3} \mathrm{H} /{ }^{14} \mathrm{C}$ ratio in DGTS (a) and DGTA (ㅁ). Double labelled DGTS was prepared by incubation of cells with $\left[2-{ }^{3} \mathrm{H}\right]$ glycerol and $\left[3,4-{ }^{14} \mathrm{C}\right]$ methionine. 
among DGTS and DGTA compared. The labelling kinetics of DGTS was almost the same in both cases with the radioactivity highest at the end of the pulse and then continuously declining during the chase, as shown in Fig. 7.

In DGTA, in contrast, a simultaneous increase of label was observed with $\left[3,4-{ }^{14} \mathrm{C}\right]$ methionine (Fig. $7 \mathrm{~b}$ ) but not with $\left[1-{ }^{14} \mathrm{C}\right]$ methionine (Fig. 7a) as a precursor. This clearly indicates that the carboxyl group of methionine appears in DGTS but not in DGTA. Thus, the transformation of DGTS to the latter involves a decarboxylation and a recarboxylation in which the carboxyl group of DGTS is eliminated and replaced by a new one of which the origin is not clear yet. These results clearly demonstrate that DGTS is converted to DGTA by alteration of the polar part as an entity. Since, on the other hand, the fatty acid composition of DGTA is entirely different from the one of DGTS (Table 2), a deacylation/re-acylation process has to be postulated replacing the 14:0, 18:1 and 18:2 acids which predominate in DGTS, by 18:0,18:1, 18:2 and 22:5 acids which are the major components of DGTA.

In order to elucidate this process, cells were incubated with $\left[1-{ }^{14} \mathrm{C}\right]$ oleate and the radioactivity was measured in the fatty acids during the pulse-chase experiment. At the end of the pulse, the label appears mainly in 18:1 and 18:2 acids, as shown in Fig. 8.

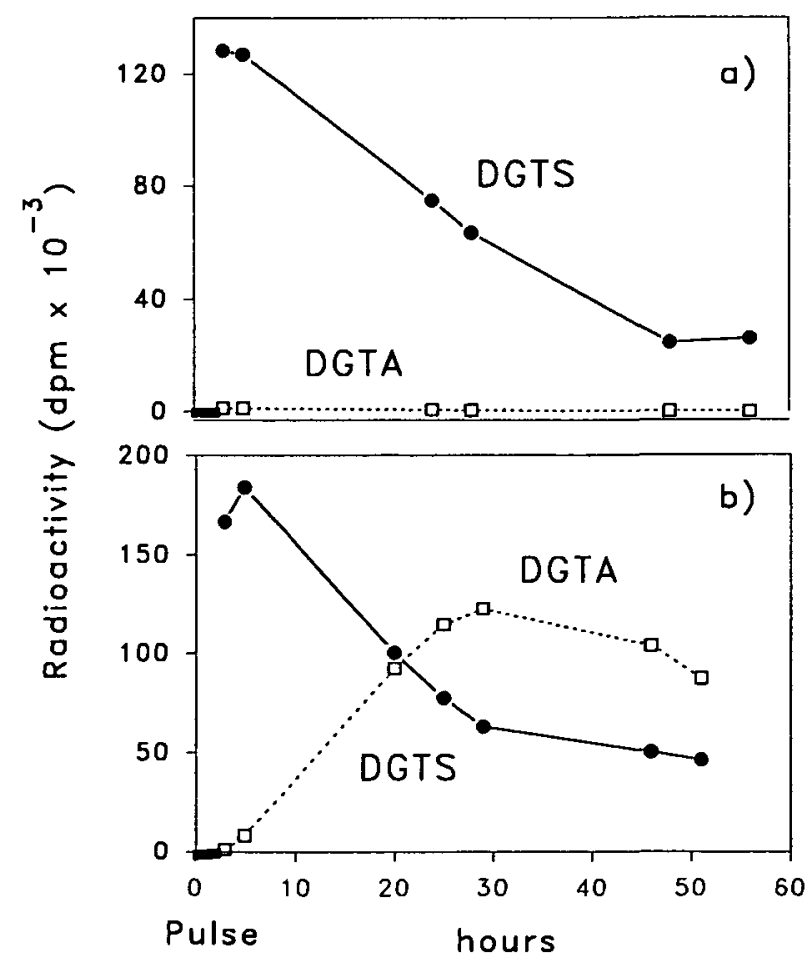

Fig. 7 Labelling of DGTS and DGTA after incubation of cells of $O$. danica with $\left[1-{ }^{14} \mathrm{C}\right]$ methionine (a) and $\left[3,4-{ }^{14} \mathrm{C}\right]$ methionine (b).

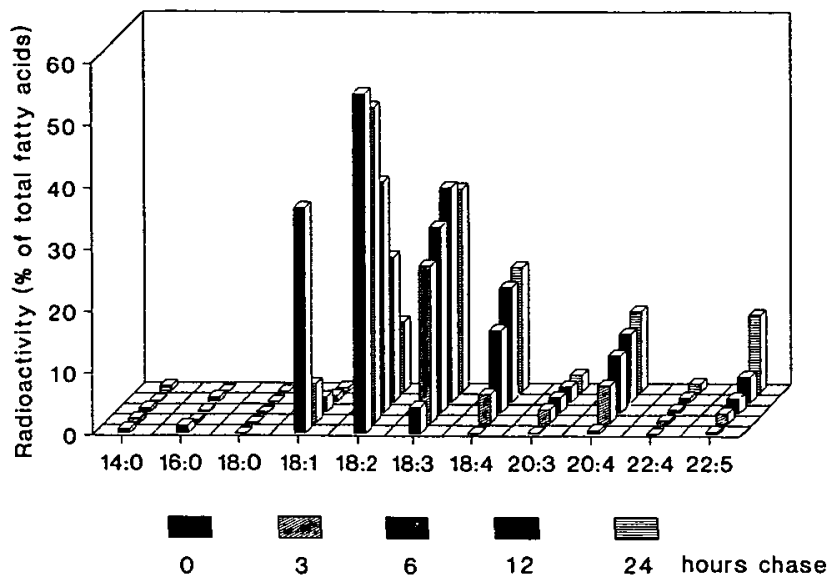

Fig. 8 Labelling of total fatty acids by incubation cells of O. danica with $\left[1-{ }^{14} \mathrm{C}\right]$ oleate.

During the chase, the label disappears very rapidly from $18: 1$, but less rapidly from $18: 2$ acids. In the same time, significant increases of label in 18:3,18:4, as well as in 20:4 and 22:5 acids are observed. This indicates that 18:1 acid is rapidly desaturated to give in a decreasing rate $18: 2$, 18:3 and 18:4 acids. Part of the $C_{18}$ acids are elongated/desaturated to give 20:4 and 22:5 acids. Since $C_{14}$ and $C_{16}$ acids were not significantly labelled, degradation of the substrate and re-incorporation of the label by de novo synthesis of fatty acids can almost be excluded.

During the pulse phase, $\left[1-{ }^{14} \mathrm{C}\right]$ oleate is mainly incorporated into DGTS and TAG, as shown in Fig. 9.

During the chase, the label rapidly disappears from DGTS and increases in DGTA, PE, PC and also in MGDG, DGDG and SQDG suggesting DGTS to be a very potent primary acceptor of exogenous oleate which later on

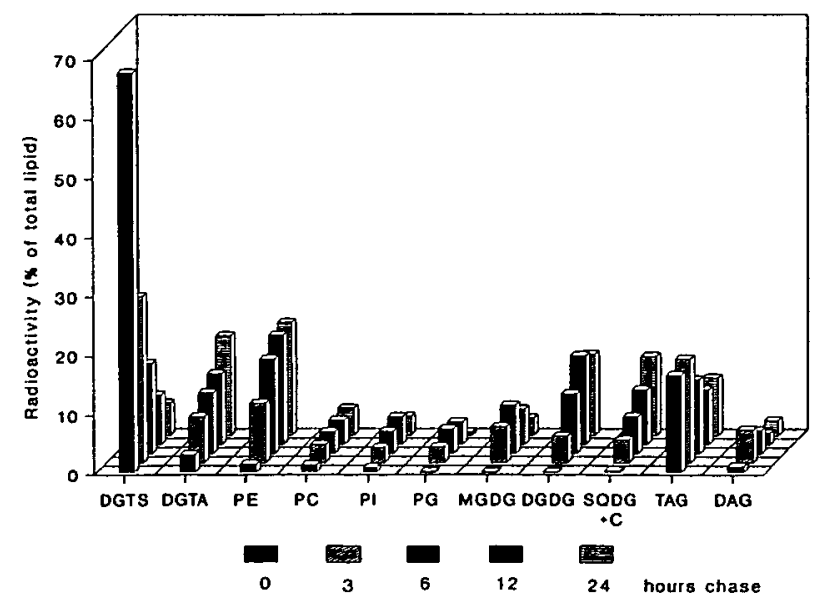

Fig. 9 Labelling of different lipids of $O$. danica on incubation of cells with $\left[1-{ }^{14} \mathrm{C}\right]$ oleate. 


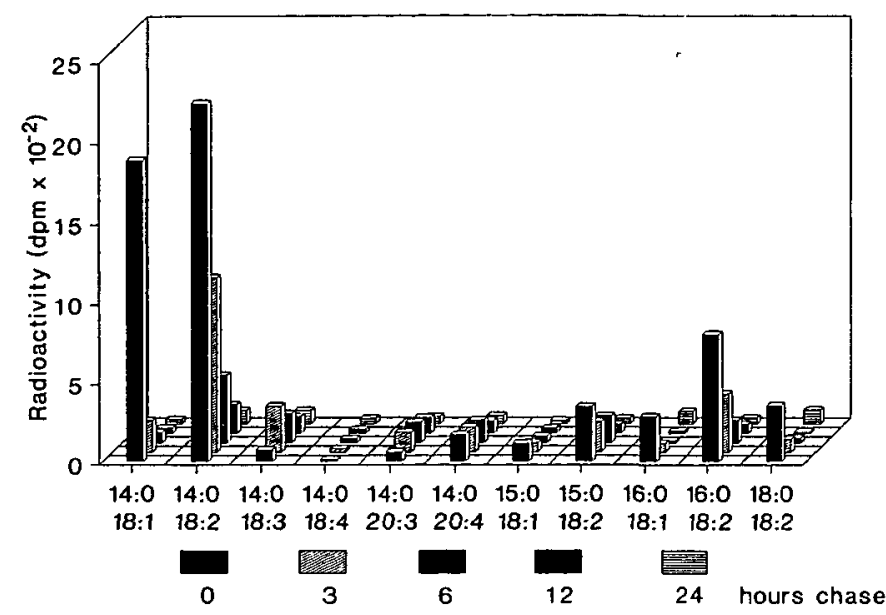

Fig. 10 Labelling of different molecular species of DGTS after incubation of cells of $O$. danica with $\left[1-{ }^{14} \mathrm{C}\right]$ oleate.

is rapidly transferred from this lipid to other polar lipids. The decline of label in MGDG during the experiment may be explained by the precursor role of this lipid in the biosynthesis of DGDG. Since the label in DGTS is almost limited to molecular species containing 18:1 and/or 18:2 acids, as shown in Figure 10, the transfer of the fatty acids from DGTS to other lipids very likely occurs at the level of monoene or diene acids.

PE seems to be one of the important secondary acceptors of $\mathrm{C}_{18}$ fatty acids, as shown by the distribution of label in the different molecular species of this lipid in Fig. 11. During the chase, significant amounts of label primarily appear in 18:2-containing species of PE where it subsequently disappears and finally accumulates in the species containing $C_{18}$ trienes and tetraenes. This is in accordance with the

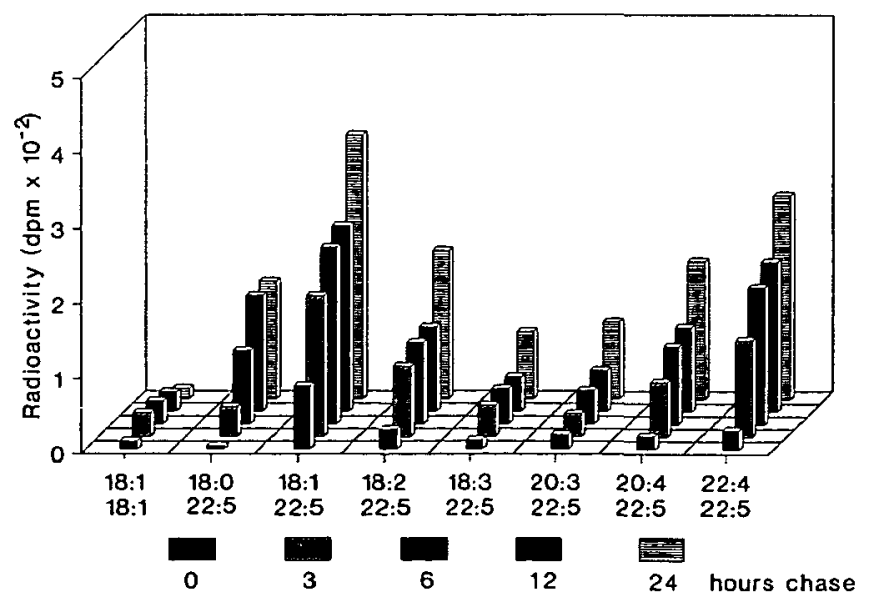

Fig. 11 Labelling of different molecular species of PE after incubation of cells of $O$. danica with $\left[1-{ }^{14} \mathrm{C}\right]$ oleate.

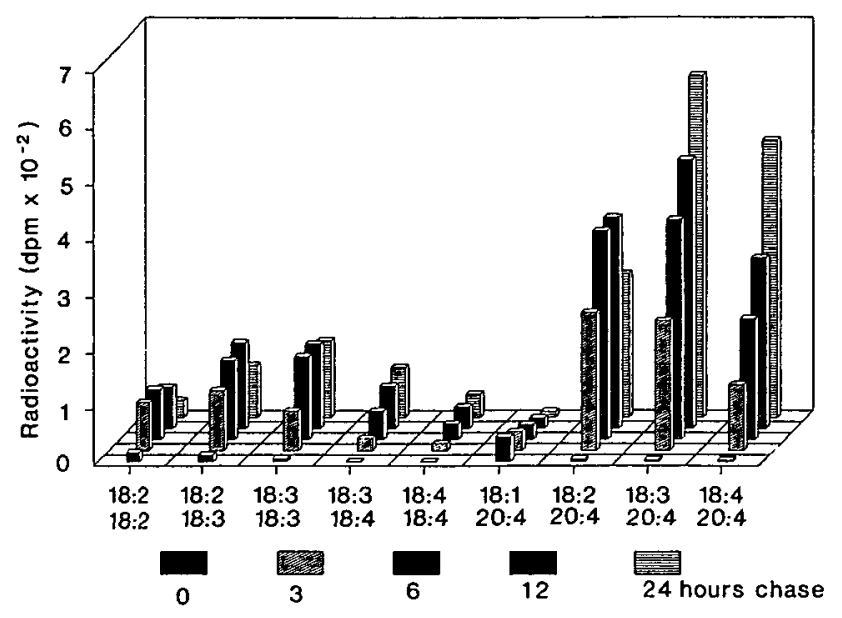

Fig. 12 Labelling of different molecular species of DGTA after incubation of cells of $O$. danica with $\left[1 .{ }^{14} \mathrm{C}\right]$ oleate.

findings on DGTS and suggests a process in which $\mathrm{C}_{18}$ monoene is desaturated on DGTS to give 18:2 acid which, in turn, is transferred from this lipid to PE and further desaturated there to give $18: 3$ and $18: 4$ acids. In order to demonstrate the processes occurring on DGTA, the labelling kinetics in the fatty acids as well as in the different molecular species of this lipid were measured, as shown in Fig. 12.

At the end of the pulse, DGTA generally contains minor amounts of label which, however, rapidly increases during the chase and is almost exclusively localized in the long-chain polyunsaturated fatty acids. Thus, the labelling kinetics in DGTA which distinctly differ from those of DGTS, suggest that DGTA is a favoured acceptor of longchain $C_{20}$ an $C_{22}$ rather than $C_{18}$ fatty acids. It is to mention that no specific molecular species have been detected which by their fatty acid composition are common to both DGTS and DGTA. Also, at the end of the pulse, the radiolabel is distributed about equally among the different molecular species of DGTS. This indicates that there is no specific molecule acting as a link between the two types of betaine lipids and suggests that rather all kinds of molecular species of DGTS are converted to DGTA.

\section{Discussion}

The results demonstrate that in Ochromonas, the betaine lipid DGTA is synthesized via DGTS by conversion of the $N, N, N$-trimethylhomoserine moiety to a hydroxymethyl- $N, N, N$-trimethyl- $\beta$-alanine moiety. This process involves a decarboxylation and a re-introduction of a new carboxyl group.

Since a similar transformation of DGTS to DGTA has also been demonstrated in Cryptomonas (Sato 1991b) we suppose that this biosynthetic pathway is likely to operate 
also in other organisms including brown algae in which only DGTA but no DGTS has been detected (Araki et al. 1991). In Ochromonas the rate of conversion of DGTS to DGTA considerably varied in different assays but seems to be generally slower in Ochromonas than in Cryptomonas (Sato 1991b) indicating that the rate of conversion may be different in different organisms. Since Cryptomonas contains 10 times more DGTA than DGTS (Sato 1991a), while Ochromonas produces 3 times less DGTA than DGTS, the conversion rate seems to correlate with the ratio DGTA/ DGTS in the cell indicating that the amount of DGTA present might be governed by the rate of transformation of DGTS. In brown algae which produce DGTA only (Araki et al. 1991), the conversion of DGTS to DGTA would be expected to be even more rapid than in Cryptomonas. Additional experiments, however, are needed to demonstrate qualitatively and quantitatively the transformation of betaine lipids in brown algae.

Since in Ochromonas, the fatty acid pattern of DGTA differs from that of DGTS, an almost complete exchange of acyl groups during conversion of the polar group was predicted. Labelling experiments with $\left[1-{ }^{14} \mathrm{C}\right]$ oleate clearly demonstrate a rapid incorporation of this exogenous substrate into DGTS but, after desaturation to 18:2 acid, a rapid exchange of the label from DGTS. This turnover with an approximate half-life time of 3 hours for 18:2 acid in DGTS seems to be much faster than the conversion of the polar group $50 \%$ of which are converted within approximately 30 hours. This suggests that, in Ochromonas, the synthesis of DGTA from DGTS is controlled by the conversion of the polar group rather than by the acyl exchange reaction. The very interesting aspect of the positional selectivity of the acyl transfer and exchange reactions has to be examined in additional studies.

Oleic acid has been used for in vivo labelling of Ochromonas (Nichols and Appleby 1969), Chlorella (Kannangara et al. 1973) and spinach leaves (Thompson et al. 1986) in which it was incorporated in all kinds of polar lipids but especially in PC. In all cases, oleic acid was desaturated to give 18:2 and a18:3 acids in a process which is considered to be lipid-linked (Harwood 1989). In Chlamydomonas (Giroud and Eichenberger 1989) from which PC is absent, and in Acetabularia (Stirnimann and Eichenberger unpublished results) which contains $P C$ in trace amounts only, oleic acid is prevalently incorporated into DGTS which in both cases serves as substrate for the desaturation. The desaturation of DGTS in Ochromonas indicates that the betaine lipid may act as substrate for desaturases also in the presence of PC.

Distinct differences in the fatty acid composition of DGTS and DGTA have also been found in organisms other than Ochromonas in which for DGTA $21 \%$ saturated and $45 \% \mathrm{C}_{20}+\mathrm{C}_{22}$ acids are typical. Similar values have also been found for DGTA from Cryptomonas (Sato 1991a) and from two brown algae (Araki et al. 1991) suggesting that generally, a high level of long-chain polyunsaturated acids are characteristic of this betaine lipid.

DGTS of Ochromonas, on the other hand, contains $43 \%$ saturated and only $5 \%$ of long-chain polyenoic acids. Since high proportions of saturated acids have also been found in DGTS from Cryptomonas (Sato 1991a) and Chlamydomonas (Janero and Barrnett 1982, Giroud et al. 1988), high contents of saturated and low levels of longchain polyenoic fatty acids seem to be typical of DGTS.

In the total fatty acids of Ochromonas, $\mathrm{C}_{16}$ fatty acids account for only $5 \%$ of the total. Similar values have also been reported by Janero and Barrnett (1982). The differences observed may be explained by the different growth conditions used. In particular polar lipids, the proportion of $\mathrm{C}_{16}$ acids varies from $0.5 \mathrm{~mol} \%$ in MGDG to $8 \mathrm{~mol} \%$ in SQDG. Since, in lipids produced by the prokaryotic (plastidial) pathway (Roughan and Slack 1982, Frentzen 1986, Heemskerk and Wintermans 1987), the sn-2 position is occupied by $\mathrm{C}_{16}$ acids which therefore account for $50 \%$ ore more of the total, the glycerolipids of Ochromonas obviously originate from the eukaryotic rather than the prokaryotic pathway. This is especially true for the MGDG and DGDG in which $\mathrm{C}_{18}$ fatty acids account for $96 \%$ and $86 \%$, respectively and which are therefore of predominantly eukaryotic structure. Among algae, highly eukaryotic galactolipids have also been found in Acetabularia (Eichenberger and Gerber 1987) and in Cryptomonas in which they may be synthesized by a pathway which does not involve PC (Sato 1991a) as does the general pathway suggested by Roughan and Slack (1982).

As to the betaine lipids of Ochromonas, basing on their low content in $\mathrm{C}_{16}$ acids, a mainly eukaryotic structure is suggested, although the positional distribution of the high amount of 14:0 acid and its origin have to be cleared up. These facts clearly reveal the necessity of further detailed studies on the glycerolipid biosynthesis in algae and a critical examination of the applicability to lower plants of the general concept of biosynthesis.

This work has been supported by Grants 3.061-0.87 and 3129880.90 of the Swiss National Science Foundation. We thank Dr. C. Müller, Hans Gfeller and Andreas Stämpfli (Dept. of Organic Chemistry) for their technical assistance in mass spectrometry and nuclear magnetic resonance.

\section{References}

Aaronson, S. and Baker, H. (1959) A comparative biochemical study of two species of Ochromonas. J. Protozool. 6: 282-284. Araki, S., Eichenberger, W., Sakurai, T. and Sato, N. (1991) Distribution of diacylglycerylhydroxymethyltrimethyl- $\beta$ alanine (DGTA) and phosphatidylcholine in brown algae. Plant 
Cell Physiol. 32: 623-628.

Borch, R.F. (1975) Separation of long chain fatty acids as phenacylesters by HPLC. Anal. Chem. 47: 2437-2439.

Brown, A.E. and Elovson, J. (1974) Isolation and characterization of a novel lipid, 1(3),2-diacylglyceryl-(3)-O-4'-(N,N,N-trimethyl)homoserine, from Ochromonas danica. Biochemistry 13: 3476-3482.

Eichenberger, W. (1976) Lipids of Chlamydomonas reinhardtii under different growth conditions. Phytochemistry 15: 459463.

Eichenberger, W. (1982) Distribution of diacylglyceryl-O-4'$(N, N, N$-trimethyl)homoserine in different algae. Plant Sci. Lett. 24: 91-95.

Eichenberger, W. and Gerber, A. (1987) Lipids of Acetabularia mediterranea. Composition, cellular localization and biosynthesis. In Metabolism, Structure and Function of Plant Lipids. Edited by Stumpf, P.K., Mudd, J.B. and Nes, W.D. pp. 637639. Plenum Press, New York.

Frentzen, M. (1986) Biosynthesis and desaturation of different diacylglycerol moieties in higher plants. J. Plant Physiol. 124: 193-209.

Giroud, C. and Eichenberger, W. (1989) Lipids of Chlamydomonas reinhardtii. Incorporation of $\left[{ }^{14} \mathrm{C}\right]$ acetate, $\left[{ }^{14} \mathrm{C}\right]$ palmitate and $\left[{ }^{14} \mathrm{C}\right]$ oleate into different lipids and evidence for lipid-linked desaturation of fatty acids. Plant Cell Physiol. 30: 121-128.

Giroud, C., Gerber, A. and Eichenberger, W. (1988) Lipids of Chlamydomonas reinhardtii. Analysis of molecular species and intracellular site(s) of biosynthesis. Plant Cell Physiol. 29: 587595.

Harwood, J. (1989) Lipid metabolism in plants. Crit. Revs. Plant Sci. 8: 1-43.

Heemskerk, J.W.M. and Wintermans, J.F.G.M. (1987) Role of the chloroplast in the leaf acyl-lipid synthesis. Physiol. Plant. 70: 558-568.

Janero, D.R. and Barrnett, R. (1982) Comparative analysis of diacylglyceryltrimethylhomoserine in Ochromonas danica and Chlamydomonas reinhardtii 137 +. Phytochemistry 21: 47-50.

Kannangara, C.G., Jacobson, G.S. and Stumpf, P.K. (1973) In vivo biosynthesis of $a$-linolenic acid in plants. Biochem. Biophys. Res. Commun. 52: 648-655.

Mazotti, F. (1990) Diplomarbeit University of Bern.
Nichols, B.W. and Appleby, R.S. (1969) The distribution and biosynthesis of arachidonic acid in algae. Phytochemistry 8: 19071915.

Pringsheim, E.G. (1955) Ueber Ochromonas danica n. sp. und andere Arten der Gattung. Arch. Mikrobiol. 23: 181-192.

Roughan, P.G. and Slack, C.R. (1982) Cellular organization of glycerolipid metabolism. Annu. Rev. Plant Physiol. 33: 97-132.

Sato, N. (1988) Dual role of methionine in the biosynthesis of diacylglyceryltrimethylhomoserine in Chlamydomonas reinhardtii. Plant Physiol. 86: 931-934.

Sato, N. (1991a) Lipids in Cryptomonas CR-1. Ocurrence of betaine lipids. Plant Cell Physiol. 32: 819-825.

Sato, N. (1991b) Lipids in Cryptomonas CR-1. II. Biosynthesis of betaine lipids and galactolipids. Plant Cell Physiol. 32: 845851.

Sato, N. and Furuya, M. (1984) Distribution of diacylglyceryltrimethylhomoserine in selected species of vascular plants. Phytochemistry 23: 1625-1627.

Sato, N. and Furuya, M. (1985) Distribution of diacylglyceryltrimethylhomoserine and phosphatidylcholine in non-vascular green plants. Plant Sci. 38: 81-85.

Sato, N. and Kato, K. (1988) Analysis and biosynthesis of diacylglyceryl- $N, N, N$-trimethylhomoserine in cells of Marchantia in suspension culture. Plant Sci. 55: 21-25.

Thies, W. (1971) Schnelle und einfache Analyse der Fettsäurezusammensetzung in einzelnen Raps-Kotyledonen. $Z$. Pflanzenzüchtg. 65: 181-202.

Thompson, G.A., Jr., Roughan, P.G., Browse, J.A., Slack, C.R. and Gardiner, S.E. (1986) Spinach leaves desaturate exogenous $\left[{ }^{14} \mathrm{C}\right]$ palmitate to hexadecatrienoate. Plant Physiol. 82: 357362.

Vogel, G. and Eichenberger, W. (1990) Biosynthesis and metabolism of betaine lipids in Ochromonas danica (Chrysophyceae). In Plant Lipid Biochemistry, Structure and Utilization. Edited by Quinn, P.J. and Harwood, J.L. pp. 235-237. Portland Press Ltd., London.

Vogel, G., Woznica, M., Gfeller, H., Müller, C., Stampfii, A.A., Jenny, T.A. and Eichenberger, W. (1990) 1(3),2-Diacylglyceryl-3(1)-O-2'-(hydroxymethyl)( $N, N, N$-trimethyl)- $\beta$-alanine (DGTA): a novel betaine lipid from Ochromonas danica (Chrysophyceae). Chem. Phys. Lipids 52: 99-109.

(Received January 28, 1992; Accepted March 11, 1992) 